\title{
Strategic human resource management and \\ leadership of cultural organisations in the 21st century
}

\section{Isidora Thymi*, Eugenia Bitsani and Stavros Pantazopoulos}

\author{
Department of Business and Organization Administration, \\ University of Peloponnese, \\ GR 241-00 Kalamata, Greece \\ Email: i.thymi@teipel.gr \\ Email: ebitsani@gmail.com \\ Email: stavpant1@teipel.gr \\ *Corresponding author
}

\begin{abstract}
The cultural sector today operates in a global environment that is constantly changing at a rapid pace. In order to respond to this highly competitive environment, cultural organisations and institutions need to apply modern strategic methods, implementing best practices and tools, in order to achieve the successful development of human resources. Strategy and human resource management tends to become more and more connected by giving a comparative advantage to cultural organisations and entities. The survey was conducted through interviews, following a semi-structured questionnaire. The main findings of the research were the following: Kalamata's Lyceum Association of Greek Women implements a strategic management of its human resources, there is a strong element of 'organisational commitment', due their volunteer character of the staff. The KLCoGW uses its unique culture in all its aspects to maintain a competitive advantage.
\end{abstract}

Keywords: cultural entities; strategy; strategic human resources; HR development; competitive environment; Lyceum of Greek Women.

Reference to this paper should be made as follows: Thymi, I., Bitsani, E. and Pantazopoulos, S. (2022) 'Strategic human resource management and leadership of cultural organisations in the 21 st century', Int. J. Cultural Management, Vol. 1, No. 1, pp.58-79.

Biographical notes: Isidora Thymi is a special teaching staff specialising in public administration at the University of Peloponnese. She holds a Master's degree in Cultural Organisation Management. Her research interests lie in the fields of public administration and cultural management. Until 2019, as a laboratory technical staff in University of Peloponnese (ex. Technological Educational Institute of Peloponnese), she participated in many committees. She has extensive experience in research projects co-funded by the European Union.

Eugenia Bitsani, Political Scientist, has both academic and entrepreneurial experience in the domain of cultural studies and cultural, and intercultural policies. She holds the position of Professor at the University of Peloponnese in the field of cultural policies - cultural management and intercultural relations. As an Academic Professor she applies interdisciplinary and transdisciplinary 
methods to the study of regional man-heritage-landscape systems, national/local/ identity - art sand strategies A large number of her publications about the previously mentioned scientific fields are published in English, in French, in Italian and in Greek.

Stavros Pantazopoulos is a postdoctoral researcher at the University of Peloponnese. He received his $\mathrm{PhD}$ in Social Policy from Panteion University, holds BA in History and Archaeology, MA in Historic Demography and MSc in Cultural Organisations Management. His research interests lie in the fields of economic and social history of Greece, social policy and social demography.

\section{Introduction}

Ricoh Corporation's Hisao Yuasa, spokesperson for the Japanese administration, says: "We start with the assumption that we cannot please our customers if our own employees are not happy. Satisfaction deriving from work is a prerequisite for achieving high quality. The duty of senior executives is to remove obstacles that do not allow employees to perform according to their capabilities".

In present day, we are witnessing the emergence of the Fourth industrial revolution. This revolution, unlike the three previous, comprises of technology, artificial intelligence, automation, robotics, the internet of things, autonomous vehicles, 3-D printing and cognitive computing. The speed of current breakthroughs has no historical precedent in the world. Moreover, it runs through almost every industry, market, every country, governments and our lives (Deloitte, 2017).

In order to maintain competitive in the marketplace, organisations are obliged to possess capabilities, strategy, culture, skills to drive innovation and technology to meet customer needs. So as the transformation journey starts, a change management would be necessary to align the organisation and design the right intervention to deliver new products and services.

The internet, as the largest operator for the distribution of information, combines the advantages of a single message, the media and personalised information, giving a new range of possibilities for communication, penetration and growth to cultural entities, as it enables connections to information, entertainment and communication anytime and anywhere (Bitsani et al., 2016).

In this framework, the concept of strategic planning is a vital element for the success of an organisation, which defines the mission, vision, objectives, and the means in order to achieve them. If we want to give a definition of what Strategy is, we could say that Strategy is to place the business in its environment. The essence of the strategy lies in creating competitive advantages of the future, faster than competitors imitate what you currently possess [Clardy, (2008), p.183] and to perform activities differently than opponents [Porter, (1996), pp.61-78].

Cultural entities, through their strategic planning, motivation and empowerment of human resources, talent acquisition and improvement initiatives, maintain a high level of quality. Organisations through education, empowerment policies and programs transform their staff into a powerful resource that adds value to the provision of services and products with direct recipients of their external 'clientele'. According to Bitsani, "the big 
and successful business is done by people; the quality difference is made by people-whether they run or just perform" [Bitsani, (2006), p.15; 2013].

Human resources are one of the most important determinants and leading factors that defines the success of an organisation in a competitive environment. Some of the features of human resources management are: the diversity, many models and practices vary within organisations. In addition, the nature of human resources that is committed to engagement, with the concepts of reciprocity and the high commitment to supporting human resource management. People and their talents are considered 'human capital', One of the original academic backgrounds of HRM is the notion that people and their collective skills, abilities and experiences should be considered as a valuable asset and a source of competitive advantage rather than cost [O'Riordan, (2017), p.8].

The main purpose of this paper is to highlight how the cultural entities and specifically the Hellenic Lyceum of Kalamata, through specific strategies implemented, develops a cultural quality policy and intervenes in the cultural development of the City of Kalamata. Managing human resources should be considered a strategic function of a cultural organisation and one of the decisive prerequisites for gaining a competitive advantage.

The present study is a part of a wider research concerning the human resources in the cultural sector. The main topic of this study is the recording and analysis of the theoretical and conceptual framework of the strategic development of cultural organisations through strategies for the development of their human resources. Then, through the case study, we identify whether human resources development strategies are implemented in the Lyceum Association of Greek Women in Kalamata.

The research is developed on two levels: during the examination of the internal environment and the development of human resources strategies, main research questions were asked such as what are the goals and prospects of KLCoGW, which are the practices of developing and empowering human resources in order to have the best results and how do they contribute to administrative efficiency and quality of services. Also, if the employees share the beliefs of the association - and if there is an 'organisational commitment', what role do human resources professionals play in this massive transformation process and how will the role of human resources be central to a model from the inside out, in a process of changing the organisational culture.

The second level examines the intervention of the KLCoGW in the external environment. In particular, the research question asked at this point is how the cultural 'product' contributes to the economic, social and cultural development of the City of Kalamata.

In order to develop the theoretical argument of the study, material from secondary sources was drawn via Greek and foreign literature, legislative enactments, articles, conferences and websites.

The methodological approach to this part of the research paradigm/example is based on tools and techniques of qualitative research method. The qualitative method follows the technique of personal interviews and participant observation during the field study, as well as the analysis of archive material, cultural studies and the SWOT analysis technique.

The research findings highlight the importance of human resources development as a strategic development choice for a modern cultural organisation. The strategy of every 
cultural organisation in the dawn of the 4th industrial revolution has a clear roadmap for digital transformation, which changes radically all functional structures, including the management of human resources. Korhonen et al. (2015) in 'IT in Enterprise Transformation' points out the fundamental consequences on employee behaviours due to digital changes and continuous unlimited connectivity. In this framework the important key is the leadership. Cultural organisations need to discover how to manage the interaction of the digital age and human resources in order to achieve success in the future.

\section{The necessity of strategic management in cultural sector}

Since the beginning of the 21 st century, the production of cultural goods is gradually transformed into digital, shaping a new reality into the cultural context. In addition, the management methods of producing cultural units are now carried out digitally, while, through the activation of automated decision-making systems, their digitised content is transmitted quickly, to every part of the earth that has the basic digital equipment.

In addition to opening new dissemination channels, the digital age has brought about tremendous changes at the heart of creation. It is clear that creators of a local community can gain more visibility thanks to new technologies. Independent musicians, for example, have access to a wealth of digital media and tools that enable them to distribute, advertise and promote their songs online and communicate directly with their audience (Bitsani et al., 2016). The proliferation of connected devices and the rapid expansion of 'self-publishing' applications have allowed all users-consumers to become potential artists. At this point, we should mention the experience of Colombian musician Carlos Muñoz, who became known for recording and editing an entire album, using his mobile phone.

When asked how technology affects creativity, he said: "technology contributes a lot to the cultural development of society. I think 'digital' artists become people who create art and create a new world" (Kulesz, 2014). So, the penetration of new technologies in the field of culture changed the way they are promoted, a fact that attracted new categories of audience, e.g., adolescents, who did not belong to the traditional museum audience or an audience from financially weak strata who were unable to attend an expensive cultural production (e.g., opera, etc.). New technologies enable a wider, global audience to interact, communicate and create their own content within a valid cultural environment. This horizon demonstrates the critical role of human resources and empowers people to cope with the new requirements of the modern era. At the same time, the strategic management of human resources and leadership play an equally important role in this direction (Bitsani, 2013).

Strategic management in cultural sector is an essential element that drives to success. It can affect the success or failure of a cultural entity and become one of the most sustainable competitive advantages. There are a few points to prove that an enterprise's human staff is of great importance. The effective management of the human resources can give the company a competitive advantage and the same time is created a strategy of creating common value under the intervention of HPM systems [Bitsani et al., (2016), pp.40-41; Mohapatra et al., 2020; Xirotiri-Koufidou, (2001), pp.61-62].

The objectives of human resources management [based on Armstrong and Taylor's (2015) theoretical framework], are to support the organisation to achieve its goals by 
developing and implementing human resources strategies that contribute to the development of a high-performing culture, securing talented and specialised leadership, creating a positive working relationship between management and employees and a climate of mutual trust [Bitsani, 2006; O'Riordan, (2017), p.8]. At the same time strategic human resource management (SHRM) has been described by Boxall (1996) as an interface between HRM and management strategy. A skilled and competent workforce is considered to be of fundamental importance for the competitive advantage and SHRM, which is oriented precisely on recruiting, supporting and developing high-quality employees [O'Riordan, (2017), p.10] and managing the human factor as a competitive tool [Verma, (2012), p.42].

However, the key element of strategic human resources management systems is that they are linked to the business and strategic initiatives of an enterprise [Becker et al., (1997), p.41; Bitsani, 2013]. Over the last decade, researchers and human resources specialists have focused their attention on issues such as:

- firstly, what is the key element that determines whether an organisation adopts a strategic approach to managing human resources and how does the HR strategy form

- secondly, issues related to policies and practices that make up different human resources strategies.

Does HR strategy really matter? For organisational practitioners looking for ways to gain a competitive edge, the consistency of strategic choices for human resources and the performance of the company is certainly the key factor [Bratton, (2005), p.38] ${ }^{1}$. According to Jackson et al. (2014), the field of strategic human resource management haw a long and rich tradition.

For Snell et al. (1996), SHRM is interpreted as "an organizational system aimed to achieve a viable competitive advantage through people". For others, however, SHRM is seen as a process, "the process of linking human resources' practices with business strategy" [Ulrich, (1997), p.89]. Similarly, Bamberger and Meshoulam (2000, p.6) describe SHRM as "the process with which organizations seek to associate the members' human, social and intellectual capital with the strategic needs of the enterprise" [Bratton, (2005), p.45-46] $]^{2}$.

According to O'Riordan, in organisations that have adopted the SHRM, it is possible to identify some key features: there is an organisational philosophy that supports the management of people (sometimes described as a 'great idea', for example 'relief of global poverty' for a third world agency or 'customer service' for retail trade organisation). Focuses on critical issues and results, people and their skills, knowledge and experiences are considered as 'competitive resources'. There is a planned approach to resources (not just numbers, but also skills and capabilities). It is preferred the long-term rather than the short-term value in the organisation. The full range of human resource management activities is concentrated in an integrated way [Bitsani, (2013), p.49; O’Riordan, (2017), p.11].

In this framework and point of view as well, studies concerning empowerment, have suggested that acceptance of workers is a key factor in administrative and organisational effectiveness (Moye et al., 2005). Organisational empowerment is the transfer of the power towards the lowest organisational units and ultimately to the administrative staff [Spiraki and Spirakis, (2008), pp.6-70]. The psychological approach to empowerment 
focuses on administrative practices that the employee perceives to exercise effective control over important work [Potterfield, (1999), p.51].

There are three closely interrelated key elements which are the keys to the success of empowering organisation employees. These include the following:

- $\quad$ attitude: it is the focal point of any progressive idea and relates to the psychological attitude (or mind) of a person or group of people in relation to a concept, central theme or idea

- commitment: this implies a sense of duty and commitment to the company

- employee engagement: this is considered the key element of the corporate success of employee authorisation (Bitsani, 2013).

As Pradhan and Panda say in their article, empowerment as a concept has a great impact on efficiency and effectiveness of the organisation and its implementation can help employees to obtain more flexibility in control of their tasks, from the other side other authors report HRE as a process by which a culture of engagement can be developed [Pradhan and Panda, (2019), pp.1-2].

\section{Strategic leadership in the era of digital transformation}

The strategy requires managers to have an opinion on all aspects of the organisation in the long run, as opposed to policies and programs that typically target organisational parts of its structure, such as departments and subdivisions. The strategy cannot be designed based on a narrow operational structure. It is important for everyone to understand that their position in the organisation is linked to all of the activities (Bitsani et al., 2016).

The peculiarity of the nature of cultural organisations, requires cultural managers, not to exhaust their role in the light of a civil service mentality, but to operate a 'trial of invisible heroes', with passion, imagination and responsibility, in a process of continuous information and training, trying to manage beyond the problems that are often created by the artists themselves, who consider themselves as 'authorities' of the specific sector. It is common for either elected officials or artists to be unaware of the specific details of the cultural space, the difficulties it faces, and the people involved in it. The result of all this is the non-existence of a complete operation and the effort of the manager to converge the differences so that there is a total intervention [Bitsani, (2004), pp.114-115].

A good cultural manager should combine technical skills and special knowledge, interpersonal capabilities and an overall and holistic view of the organisation as well as specific problems that faces. According to Fopp (1988), no matter how important the managerial and organisational skills of an individual are, they alone are not enough to manage a cultural organisation.

Cultural organisations have some substantial differences from companies (they usually do not seek for profit, they often have restrictions on how they operate, they aim for values and not profit such as education, social awareness, entertainment, aesthetic pleasure, preservation of historical memory, etc.) and therefore require from the person who is responsible for the management, appropriate skills and familiarity with the object, 
and above all, faith in the value of cultural goods [Economou, (2003), pp.71-75]. Research shows that employees develop a sense the feeling of ownership in situations where they understand that they are appreciated by managers and organisations [Bitsani et al., 2016; Uslu, (2015), p.1465].

Cultural property managers should adopt principles of management and administrative coordination and orientation in the internal environment of the organisation, rewarding and encouraging employees, ensuring job stability and development within the general (public) interest, in order to effectively manage (Bitsani, 2013). The manager should review, develop, and enforce policies in order to ensure a high level of ethics throughout the organisation. He should play an important role in establishing an innovative organisational mentality, fostering the creativity and innovation of employees in cultural organisations, taking on the role of a transformational leader, a leader who creates a work environment where followers feel empowered to seek innovative approaches on doing their job [Jung et al., (2003), p.530-531].

In addition to the general principles that managers must adopt, their main areas of activity are planning (business plan), administration (mainly concerns staff processes selection - training - supervision - encouragement - consulting - communication), organisation (structure development and grouping of tasks) and the control of the achievement of the objectives [Economou, (2003), pp.81-83].

In the digital age we live in, the development programs of the 'society of information for all' and the coordinated actions of digitisation of the cultural heritage that are taking place, especially in the last years, have made necessary the application of New Technologies in the new context of digital and virtual culture. So as the perception of dissemination and promotion of cultural goods by cultural organisations, cultural industries must be adopting a value-centric approach to organisational culture to identify cultural values critical for digital transformation success (Hartl and Hess, 2017). These new data make it a prerequisite for a good manager to monitor daily and at all levels the current trends applied at both European and international level, applying the principles of general (public) interest, provided that diversity and quality of cultural goods through new technologies enhances competitiveness, while their mass production shapes superiority in a global network [Bitsani et al., (2016), p.37].

In these difficult conditions of being a pioneer leader - a good cultural manager, is vital to constantly maintain and improve the empowerment of employees in the organisation [Ongori, (2009), p.11]. Of course, in addition to the people with whom the cultural manager has a conventional relationship, there are a number of other people who are closely related to the internal environment of each cultural organisation. These relationships should also be addressed. In the arts industry, there may be specific issues related to, for example, the connection between space and a tour or collaboration with creative artists [Hill et al., (2011), p.316].

Culture managers need to focus on human resources in various fields, such as on personal development, in order to become active users of new services, to acquire new skills, to embrace new attitudes and behaviours, to be more flexible and, eventually, to take on more responsibilities. Today's conditions require more than ever to invest in digital skills, which allow us to continue to be productive, to collaborate and to manage situations remotely. Also, there is a wealth of best practices, new technology and digital tools that organisations of all sizes can use or adapt to their needs (Vrasidas, 2020). 
Cultural units must face with maturity and prudence the difficult conditions experienced by society and the development strategy should be directed in digital ways, ensuring their sustainability and competitiveness. Also, culture managers will be able to formulate appropriate strategies for the development of social responsibility by acquiring a dynamic approach to their leadership style (Salamzadeh et al., 2019). Ultimately, that is the role of culture managers ${ }^{3}$.

Therefore, good leadership must be depicted on all levels of the organisation. Good leadership inspires subordinates, creates a vision that the organisation must follow and empowers employees through training and development in order to implement it [Ongori, (2009), pp.11-12]. Many studies have been composed regarding the role of leadership, proving that certain leadership behaviours are clearly correlated with commitment structures, factors such as motivation, organisational commitment, satisfaction, the quality of the work-life relationship, communication, power sharing, engagement, characterising leadership as inspiring and visionary, resulting in higher levels of employee involvement and fulfilment of their expectations [Bedarkar and Pandita, (2014), pp.111-113; Gosetti, 2020].

\section{The research example of the Association 'Lyceum of Greek Women' in Kalamata}

\subsection{Research methodology}

The application of mixed methods in research, where quantitative and qualitative methods are combined, is increasingly recognised and considered reliable, as it can capitalise the advantages of qualitative and quantitative studies. The methodology followed to fulfil the purpose and goal of this research is qualitative and quantitative research through the technique of triangulation. According to Denzin (1978) by the term 'triangulation', we mean the 'mixing of many methods in the study'.

In other words, it is the use of more than one research technique in the study of the same research field, where each is used to verify the results of the other. Olsen characteristically states that when a technique is used later it verifies but also develops the results of the previous one [Evangelou, (2014), p.113]. The difference between quantitative and qualitative data is essentially the difference between numerical and non-numerical data [Babbie, (2011), p.63].

In particular: the first part of the research includes the valuable tool of interview and semi-structured questionnaire. The questionnaire consists of 37 questions, through which the results of the interviews that will be presented below, were developed. The method of interview was chosen because it is one of the main qualitative tools, and is based on a framework of interaction and communication between people, with the aim of extracting information about the object of research. According to Mialaret, it is an attempt to form a 'mental content' [Mialaret, (1997), p.148]. Tuckman defines it as an opportunity to 'enter' and to discover what is going on in the subject's mind, revealing aspects of his/her personality and recognising behaviours [Paraskevopoulou-Kollia, (2008), p.3].

With the method of personal interview, we have the following advantages: The respondent has already agreed to answer the questionnaire, as he has been already informed about the content of the questionnaire, has accepted to participate in the 
meeting and it is allowed to clarify questions that may not have been understood. [Minichiello et al., (1995), pp.76-104]. It is also ensured that the questionnaire is completed by the appropriate person within the organisation. An important parameter is that we do not procrastinate with data collection. On the contrary we achieve a higher response rate, because if we choose to collect data through mail interviews, we risk not having answers or being delayed [Babbie, (2011), p.418].

In the context of qualitative research, interviews were conducted with several members of the human resources of the Lyceum of Greek Women, founding members, teachers, animators of educational programs, etc.

The framework of the questionnaire that the interviewees were asked to answer in this research were classified into the following categories/groups which were derived from the research question and the research hypotheses:

First category of the questionnaire:

- In which way is the administration implemented?

- Which are the key strategic objectives:

- In which way is the human resources of KLCoGW developed - strengthened?

Second category of the questionnaire:

- What is the role of human resources in the development of KLCoGW and how does that affect the cultural development of the local community?

- Is it an essential element of the identity of the city?

- What is the element that unites and motivates them in order to lead to the development of the organisation?

- What emotions do they get from their participation?

- What differentiates KLCoGW from any other organisation?

Through the interviews, the strategy, the financial planning, the activities, the development prospects and the viability of the Lyceum of Greek Women were analysed. The tactics of human resources' empowerment and the effort made for continuous development and gaining experiences through seminars and training programs were highlighted. The contribution to the economic and cultural development of the local community was noted. Moreover, the interviewees also referred to the social face of KLCoGW and its special contribution to the great economic and social problems that citizens face today.

It is noteworthy that, despite the great offer and support it provides to both families with financial problems and people with health problems, beyond the local borders of the city, it keeps a very low profile. In addition, the services provided were analysed, in the basis of how they share their knowledge, what unites and mobilises them, the experiences they gain through their involvement in $\mathrm{KLCoGW}$ and what they believe differentiates KLCoGW from any other organisation.

It is worthy of mention that all questions asked the interviewees were based in the context of ethics, trying not to put them in a difficult position and embarrassment [Babbie, (2011), p.446]. 


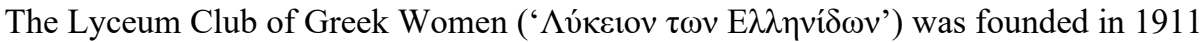
by Callirrhoe Siganou-Parren, a pioneer of the feminist movement in Greece and the country's first woman journalist. It is a volunteer organisation, which, in the 103 years of its existence, has played an active and important role in the preservation and presentation of Greek cultural traditions and folk customs.

Today it maintains its dynamic presence in Greek society thanks to the voluntary service of its many dedicated members in Athens, in its 51 branches all over Greece and in its 16 bureaus abroad. The Lyceum Club of Greek Women has been awarded twice by the Greek Academy and in 2012 it has been certified as a consultative organisation of the UNESCO Intergovernmental Committee for the Safeguarding of the Intangible Cultural Heritage (http://www.lykeionellinidon.gr/index_en.html).

The Kalamata's Lyceum Club of Greek Women (KLCoGW) was founded for the first time in 1915, but later it was dropped and practically abolished. In 1967, during the tenure of the late Kostas Koutoumanos as a mayor and while President of the Central Lyceum Club of Athens was the unforgettable Chrysoula Kallia, the KLCoGW was re-established, and has continued its multiplex action ever since. It is one of the sister Lyceums that exist not only among the Greek territory, but also among Europe, America, Australia, Africa and New Zealand, and the second in size (http://www.lykelkal.gr).

This part of the survey includes the valuable tool of the qualitative interview and a semi-structured questionnaire. The questionnaire consists of 37 questions, through which the results of the interviews that will be presented below are developed. The interview was chosen because it is one of the main tools of the qualitive method, based on a framework of interaction and communication between individuals, with the aim of collecting information about the research subject. According to Mialaret, it is an attempt to form a 'mental content' [Mialaret, (1997), p.148]. Tuckman defines it as an opportunity to 'enter' the mind of the subject and discover how it works, revealing aspects of personality and recognising behavioural patterns (Paraskevopoulou-Kollia, 2008; Bitsani, 2014).

With the personal interview technique, we have the following advantages: The respondent has already agreed to answer the questionnaire, as he/she has been informed about the questionnaire content and has accepted the interview, and is also allowed to clarify any questions that are not clear to him/her [Minichiello et al., (1995), pp.76-104]. In addition, it is ensured that the questionnaire is completed by the appropriate person within the organisation. An important parameter is that when we do not procrastinate with the data collection, we achieve a higher response rate, because if we chose to collect the data via questionnaires sent through postal services, we risked getting delayed or no responses at all [Babbie, (2011), p.418]. The key questions the interviewees were asked to answer, in this research, these included:

How does management work and what are basic strategic goals of KLCoGW. How KLCoGW human resources grow - are empowered. On the other hand, which element unites them and motivates them for the favour and the development of the club, are they gain feelings from their participation and which are they. What differentiates KLCoGW from any other organisation, what is the role of human resources in the development of KLCoGW and the cultural and general development of the local community. Finally, is it an essential element of the identity of the city?

In the framework of the qualitative research, interviews were held with Mrs. Anna Mavrou, member of the Board of Directors and Commissioner of the Dance Department, as well as Mr. Tasos Mihos, Art Director, Mr. Nikos Petroulias, Dance teacher, Mr. 
Christos Tsiamoulis Choirmaster and Musician, Mr. Konstantinos Giannakopoulos and Nancy Kanellopoulou (empowerer), staff of the Exhibition Center of the Traditional Costume Museum of Kalamata Lyseum Club and one of the founding members of the Choir of the KLC Mrs. Stavroula Poulopoulou-Tsichli.

Questions to the interviewees were conducted following the ethical framework, trying not to put them in a difficult position and feel uncomfortable [Babbie, (2011), p.446]. The questions were common to all the interviewees except Ms Mavrou, with whom the subject was further developed, dragging us into the world of KLC, through the narrative of various events. Through her interview, how KLC works was imprinted to the interviewer.

Regarding the key questions the interviewees were asked to answer, in this research, these included: the main goals of $\mathrm{KLCoGW}$, according to its constitute, are the preservation of Greek traditions, the research and study of traditional costumes, the research and accurate execution of traditional dances, the recording of genuine folk traditional music and the usage of a collection of original costumes by displaying them to the general public.

The last step, and the most important of the present research, was the processing of the data collected (interview material and notes decoding as well as the classification of the information material given to us by the ECA), in order to extract the results of the findings from both interviews, as well as the questionnaires, in order to arrive at safe conclusions.

\section{Results}

\subsection{Discussion of the results}

\subsubsection{Administrative organisation of $K L C o G W$}

The Kalamata's Lyceum Club of Greek Women is essentially a women's non-profit Association with a social and cultural character. The operation of the KLCoGW is governed by the statute and its legal amendments, as it was codified and translated into the common language by the decision of the general assembly of the members of $11 / 3 / 1998$ and by the provisions of the law on associations. According to its statute, the KLCoGW is administered by a 15 -member board of directors, elected by secret ballot by the general assembly of the members every four years. The board of directors, immediately after its election, is constituted in a body following a vote among its members ${ }^{4}$. Today, L.G.W.K. numbers 300 members approximately. Its annual membership fee is 15 euros.

L.G.W.K.'s activities are distributed to work sections such as the national costumes section, the folk-dance section, the national traditions section, the national costumes workshop, the music section, the historical archive section, the educational programs section, the problems of the woman and child section, etc.

The purpose of KLCoGW is the preservation of Greek traditions, character and customs, as well as the rise and advancement of Greek women. The KLCoGW is actively involved in the teaching of traditional Greek dances. Every year, more than 7 hundred people of all ages attend classes. It has a permanent dance group, which performs dancing performances at home and abroad with great success. This group is called 'demonstration 
group', coming from the beginner groups of the dance sections. Annual children's performances of traditional character and imagination bring children closer to the roots of Greek Culture. It has a choir of traditional songs, which performs musical performances unique to their themes and artistic excellence (http://www.lykelkal.gr/) $)^{5}$.

Figure 1 KLCoGW board of directors ${ }^{\mathrm{a}}$ (see online version for colours)

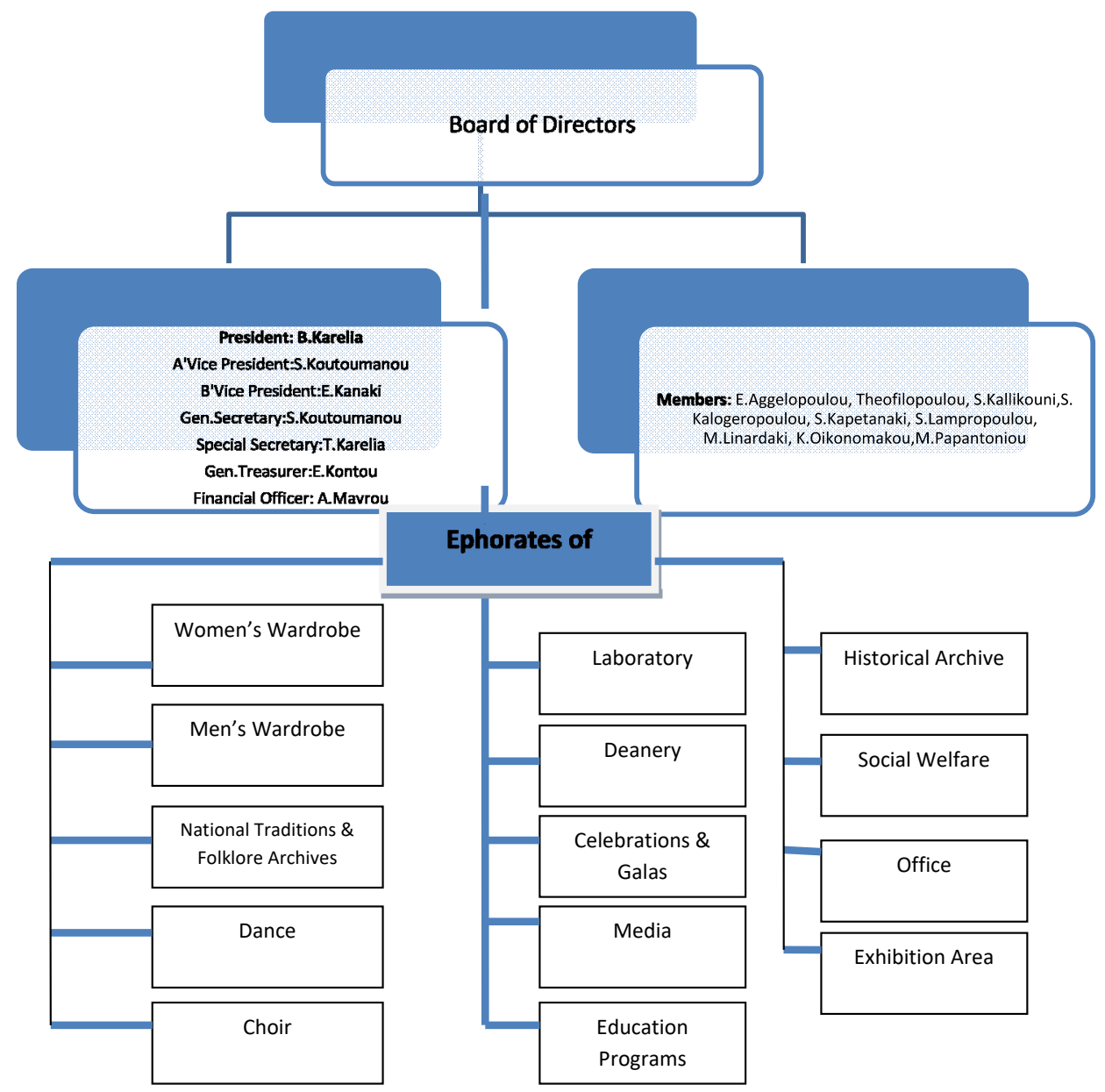

Note: aData from the interview with Mrs. Mavrou.

In addition, it is active in the field of folk publishing and digital recordings of traditional songs, has taken part in radio broadcasts and has also appeared on Greek and foreign TV, producing knowledge about Greek traditional clothing, dance, song, character and customs of Greece.

The recognition of its contribution is demonstrated by the many awards it has received both from state agencies and from social organisations for all its activities. Reports are also available in national and local press (http:/www.lykelkal.gr/). 
The KLCoGW has two buildings, one of which is privately owned and has been purchased by President and Founder Mrs. Karelia, hosting the adult dance group, the choir and the wardrobe, and in the other are housed the smaller ages ${ }^{6}$.

At a time, which is thirsty for cultural particularity, the KLCoGW, loyal to the ideas that its founders laid down forty years ago, employs all of its forces to promote its purpose, the genuine and unalterable preservation of our Greek traditional heritage (http://www.lykelkal.gr/).

Figure 2 Remunerated personnel (see online version for colours)



From the presentation of the organisational structure of the KLCoGW, we note that each person's role is clear, which facilitates the responsibilities of each sector and the coordination of tasks. Another highlight is the voluntary contribution to the organisation of the KLCoGW. The members of the board of directors support the ephorates without any remuneration and provide every possible help with the various tasks and productions.

During Mrs. Mavrou's interview, the strategy and the financial planning of the KLC were analysed, and references to KLC main activities, its development prospects and sustainability were made. She presented the empowerment techniques used for their 
human resources and the effort made for continuous development and on the job training through seminars and educational programs. KLC contributions to the economic and cultural development of the local community were noted, as well as the social side of $\mathrm{KLC}$ and its particular contribution to the major economic and social problems that the citizens face today.

It is worth mentioning that despite the great contribution and support it provides both to families with financial troubles and to people with health issues, beyond the borders of the local city, it maintains a particularly low profile. The other interviewees analysed the provided services, how they shared their knowledge, what unites them and motivates them, the teaching methods, the experiences they get through their involvement in the $\mathrm{KLC}$, and what they think differentiates KLC from any other organisation.

\subsubsection{Creating more effective KLCoGW through strategies of empowerment}

The members of the Board of Directors are in a permanent search for ways of empowering their human resources providing them with experiences, original folklore programs, inviting teachers from other places to teach, planning seminars in different regions every year, in order to continually evolve. Teaching methods such as 'demonstration' and 'mentoring' help learning and provide guidance and counselling on the development of human resources [Papalexandri and Bourantas, (2002), pp.290-291]. During the period 1991-1992, a 6-month seminar was held from all over Greece and it was then that the core of the dance group, which exists today, has been formed.

The board of directors are always close to the teachers, supporting them with any effort to improve their services, offering total help, even if the cost is great, not forgetting that it is a non-profit association that relies heavily on volunteer work. It gives them opportunities to attend seminars throughout Greece, often covering travel and accommodation costs. It is worth mentioning that for a song the dancing master Mr. Michos travelled to Meliki of Imathia in order to bring it and teach it at Lyceum ${ }^{7}$. Moreover, it is constantly trying to attract and recruit people with knowledge and experience recognised in their field.

There is the need for the necessary motivation and organisational support in order for workers to reach their maximum performance [Chytiris, (2001), p.71]. They study folklore, conduct tours in traditional settlements and museums, invite music and dance groups to present their traditions, respecting tradition and further contributing to the expertise of their human resources ${ }^{8}$. This year, for example, the Dance Department honours Thessaly, and in particular the region of Pindos, where Professor G. Dimas presented various techniques.

It is worth mentioning that the material of the seminars held each time is processed and taught throughout the year in all the relevant classes ${ }^{9}$. The human resources professionals develop a solid relationship of trust with the board of directors of the association and create methods of engaging employees and volunteers to use their best talents. Active participation and collaboration of human resources is encouraged so that those executives have the necessary knowledge to take on new roles, sometimes the role of the trainer. ${ }^{10}$

New technologies and innovative methods have been adopted following the requirements of the era (its website is upgraded, it has appeared in social media, trip 
advisor, the exhibits in the traditional costume museum are electronically recorded and digital applications are being used in its various departments).

The moral satisfaction of the perfect execution of each cultural activity is the beginning and the end for the continuation of the association. Collaboration, communication, mutual understanding and love of tradition connect all the personnel with strong ties. Its social role refers to the creation of the knowledge of tradition, the influence of attitudes and perceptions, behaviours and strengthening of bonds between people. As Mr. Michos says in his interview, "tradition is what we do for future generations, what we have found is the receipt of it".

What one understands is that the SHRM practices used help improve organisational learning. The focus of human resources policies and processes remains on the assessment of the roles and responsibilities, which are required to align in order to better perform the tasks that each person undertakes. It enhances the degree of knowledge transferred between the different members of the group. Interpersonal processes are also positively linked to team performance through team engagement, long-term responsibility to ensure success and growth. Group behaviours and positive aspects of learning are stimulated through the SHRM practice framework of the Lyceum [Alharthey and Rasli, (2011), p.10448].

\subsubsection{SWOT analysis}

SWOT analysis consist another strategic management tool that helped us even more in our study was the SWOT analysis.

Completing the SWOT analysis, in order to record the current situation at the KLCoGW and highlight the internal and external factors to achieve its goals, it is necessary to record them main conclusions and considerations for the future of this culture organisation.

Being a part of the history of Kalamata, the KLCoGW preserves its historical character constituting a living Museum of Tradition that promotes and brings to light the city's cultural heritage.

The interior of the cultural entity presents a series benefit that contribute to the fulfilment of its mission and implementation of its goals. In particular, the financial and administrative autonomy that ensures its legal status contributes to its independence from the state interventions and contributes to the implementation of his project in light of the actual requirements of society.

It has a conscientious workforce, which although is understaffed, however works efficiently, making every effort to achieve the objectives.

However, there is a lack of promotion of this local cultural element as it does not exist an organised framework for cooperation with cultural activities producers in local level. In addition, there is no organised promotion of the historical itinerary of the association to city residents and visitors as well.

There are also a number of disadvantages mainly related to administrative issues, which lead to a reduction in efficiency and a waste of time, such as the lack of staffing rules and the lack of permanent staff. 
Figure 3 SWOT analysis (see online version for colours)

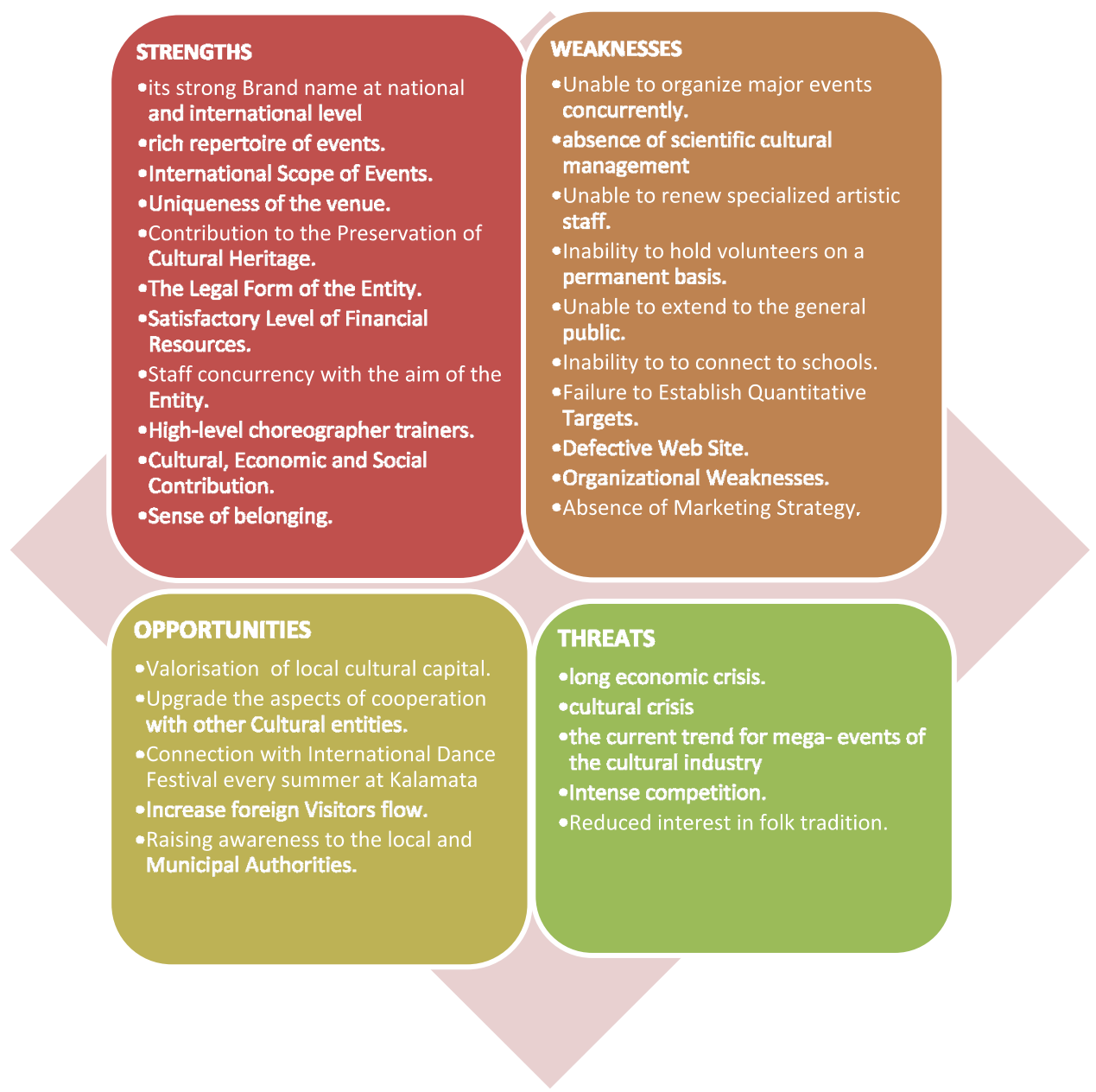

The empowerment of the staff in this entity is an ongoing research, due their volunteer character. We could say that empowerment and communication are inextricably linked to a successful organisation because empowerment is the process of enabling individuals to adopt new behaviours that further their individual aspirations and those of their organisations and communication at the organisational level helps to convey organisational goals and objectives to employees and teams within the organisation. 
Table 1 Significant points of reference of the theoretical background with research/SWOT analysis conclusions of the case study

1 The multiplex role of human resources in the internal environment is clear (Terzidis, Tzortzakis, O’Riordan, etc.)

2 Implementation of strategies for the development and empowerment of human resources (Schuler, Yean, Yahya Hill and O'Sallivan, etc.)

3 The implementation of SHRM practices is reflected in the external environment, the quality of services and the overall strategy of each organisation (Becker and Huselid, O'Riordan, etc.)
The KLCoGW makes every possible use of the talents and abilities of its human resources, creating the human productivity it needs to realise its vision. Personnel with their knowledge, skills and experience are considered a competitive resource.

The KLCoGW invests in strategic human resources development practices such as training and education, demonstration, mentoring, on the job training, strengthening the development and empowerment of its human resources but in empirical way.

The appeal of its productions not only to the city of Kalamata but also to the national public, the recognition of its brand name, the references made to it, reflect in the best way the quality of the cultural activities experienced by its 'customers'.

\section{Conclusions}

Regarding the literary review, the importance of SHRM tend to emphasise at a 'holistic' view of human capital and "the extent to which a set of development practices of an organization's employees are used and the consistency of these practices on its overall strategy" [Becker and Huselid, (2006), p.89; Bitsani, 2013, 2014; Bitsani et al., 2016].

Many studies have revealed the impact of a reward to an organisation (Dowling and Richardson, 2011) and its holistic quality management (Allen and Kilmann, 2001; Bitsani, 2013, 2014). Similarly, it is argued that if the managers wish to apply employee empowerment within an organisation, adequate rewards must be linked to the desirable behaviour of employees. In particular, an appropriate reward system should be put in place to encourage workers to take additional decision-making responsibilities related to empowerment of workers [Baird and Wang, (2010), pp.577-579; Bitsani, 2013].

Today the KLCoGW (Lykeion ton Ellinidon) maintains its dynamic presence in Greek society, thanks always to his strategic choice of investment in the voluntary service and empowerment their dedicated members, endeavouring to link its long experience in social service and in the wise administration of its cultural heritage with the new knowledge provided by modern science and technology.

Specifically, the KLCoGW uses its unique culture in all its aspects to maintain a competitive advantage. Its internal environment is embraced by a continuous process of developing and empowering human resources through personal education and development with the purpose of improving performance (Vrasidas, 2020; see also Emaan and Ali, 2020).

This dynamic organised learning activity through the enrichment of knowledge, skills, abilities and personal pleasure does not only benefit productivity and the satisfaction of human resources but also works for the benefit of the Society and society in general. The KLCoGW is not a simple dance club, it is a 'school', it teaches the Greek 
tradition, it creates values, where values are the cultural products and ideas that the people of a society appreciate, because apart from any practical value they have a great importance for them [Chytiris, (2001), p.84; Bitsani, 2013], and this is shown in a prominent way by the data gathered through the interviews.

What is revealed by the data gathered is the fact that KLCoGW empirically and emotionally implements a strategic management of its human resources that integrates traditional human resources management activities into a more general strategic planning in order to achieve its goals and vision. Human resources is the most valuable asset of the KLCoGW and a driving force to achieve its goals and fulfil its vision. The quality of the services of the Association lies in the ability to properly select and use its human resources.

Personal development plans allow every employee to grow not only in a professional but also in a personal level, for a career plan (Yean and Yahya, 2013). There is a strong emotional element of 'organisational commitment' in all its manifestations. The practices used help the Association create a distinct and significant competitive advantage by selecting and developing highly qualified and skilled personnel capable of performing its services at high levels.

In conclusion, effectiveness and efficiency of empowering people increases employee loyalty, develops actions, providing two types of services, administrative and strategic, while providing at the same time an understanding of the culture it wants to cultivate so that all of its human resources may assist with its journey of realising the vision. In addition, high employee satisfaction is a prerequisite for increasing productivity, responsiveness, quality and customer service [Sageer et al., (2012), p.32].

The creation of coordinated and sound actions, highly trained staff, new innovative applications, volunteering, ensuring good relations with local authorities and self-government are factors that help to strengthen further the existence of every cultural entity such as the example of KLCoGW. Adiguzel et al. (2020) report on this point that in today's competitive environment and global world, where the boundaries have disappeared as a result of the continuous development in communication and technology, the attitudes and behaviours of the employees in their organisations are becoming more important in terms of employees' performance, strategic human resources management (SHRM) [Adiguzel et al., (2020), p.103].

It is worthy of mention that seizing the opportunities of digital revolution, which in parallel has entered both society and the global economy, will greatly determine sustainability and prosperity. Also, with the latest developments, organisations earned the capabilities to carry out their functions more efficiently and rapidly (Baykal, 2020). An important factor in all this is the organisation to keep its course and mission (Bitsani et al., 2016).

In addition, it would be extremely interesting, at a later stage of the research, to investigate the degree of emotional intelligence of this organisation, as well as the possibility of interfacing the interaction of digital age and human resources responding to the new conditions that have been created. Smart strategies should focus on human resources, encouraging it in this new reality because, as Ram Lakshminarayanan ${ }^{11}$ points out, digitisation is rapidly changing the way we operate and create value. The complexity dynamics of the 21 st century demands a different strategic management and a cultural innovation. 


\section{References}

Adiguzel, Z., Ozcinar, F.M. and Karadal, H. (2020) 'Does servant leadership moderate the link between strategic human resource management on rule braking and job satisfaction?', European Research on Management and Business Economics, Vol. 26, No. 2, pp.103-110 [online] https://doi.org/10.1016/j.iedeen.2020.04.002.

Alharthey, K.B. and Rasli, A. (2011) 'Key role of strategic human resource management (SHRM) in advancing the degree of team learning', African Journal of Business Management, Vol. 5, No. 26, pp.10446-10451 [online] https://doi.org/10.5897/AJBM11.1663.

Allen, S.R. and Kilmann, H.R. (2001) 'The role of the reward system for a total quality management-based strategy', Journal of Organizational Change Management, Vol. 13, No. 2, pp.110-131 [online] https://doi.org/10.1108/09534810110388036.

Armstrong, M. and Taylor, S. (2015) Armstrong's Handbook of Human Resource Management Practice, Kogan Page, London.

Babbie, E. (2011) Introduction to Social Research, Kritiki, Athens.

Baird, K. and Wang, H. (2010) 'Employee empowerment: Extent of adoption and influential factors', Personnel Review, Vol. 39, No. 5, pp.574-599, Emerald Group Publishing Limited [online] http://doi.org/10.1108/00483481011064154.

Bamberger, P. and Meshoulam, H. (2000) Human Resource Strategy: Formulation, Implementation, and Impact, Sage, Beverly Hills, CA.

Baykal, E. (2020) 'Digitalization of human resources: e-HR', Tools and Techniques for implementing International E-Trading Tactics for Competitive Advantage, pp.268-286 [online] http://doi:10.4018/978-1-7998-0035-4.ch013.

Becker, B., Huselid, M., Pickus, P. and Spratt, M. (1997) 'HR as a source of shareholder value: research and recommendations', Human Resource Management, Vol. 36, pp.39-47, http://doi.org/10.1002/(SICI) 1099-050X (199721) 36:13.0.CO;2-X.

Becker, E.B. and Huselid, A.M. (2006) 'Strategic human resources management: where do we go from here?', Journal of Management, Vol. 32, No. 6, pp.898-925 [online] http://doi.org/10.1177/0149206306293668.

Bedarkar, M. and Pandita, D. (2014) 'A study on the drivers of employee engagement impacting employee performance', Social and Behavioral Sciences, Vol. 133, pp.106-115 [online] https://doi.org/10.1016/j.sbspro.2014.04.174

Bitsani, E. (2013) 'Theoretical approaches to the organizational culture and the organizational climate: exploratory research examples and best policies in health care services', Journal of Human Resource Management, Vol. 1, No. 4, pp.48-58 [online] http://doi.org/10.11648/ j.jhrm.20130104.11

Bitsani, E. (2014) 'Intercultural City Identity' and 'Human Intercultural Cities' (H.I.C). An Ontological/Dynamic Model for the Social Cohesion of Modern and Post-Modern Cities. The Research Example of Trieste Italy, Nova Publishers, NY, USA.

Bitsani, E., Kapos, P. and Cristopoulou, C.S. (2016) 'Cultural communication in the information and knowledge society: dimensions, challenges and transformations of the communication process between the European cultural organizations of the 21 st century. Case study: the communicative planning of the Athens Concert Hall', International Journal of Emerging Research in Management \& Technology, Vol. 5, No. 3, pp.36-46, ISSN: 2278-9359.

Bitsani, E. (2004) Cultural Management \& Regional Development. Cultural Policy Planning and Cultural Product, Dionicos, Athens.

Bitsani, E. (2006) Human Resource Management. Issues and Modern Approaches to the Theory of Organizational and Administrative Behavior, Dionicos, Athens.

Boxall, P. (1996) 'The strategic HRM debate and the resource-based view of the firm', Human Resource Management Journal, Vol. 6, No. 3, pp.59-75, https://doi.org/10.1111/j.1748-8583. 1996.tb00412.x. 
Bratton, J. (2005) 'Strategic human resource management', Human Resource Management, pp.31-78 [online] http://www.otaru-uc.ac.jp/ js/downloads/SP2005-PDF/SP2005Chapter2SHRM.pdf (accessed 20 March 2020).

Chytiris, L. (2001) Human Resource Management, Interbooks, Athens.

Clardy, A. (2008) 'The strategic role of human resource development in core', Human Resource Development International, Vol. 11, No. 2, pp.183-197 [online] http://doi.org./10.1080/ 13678860801932998.

Deloitte University Press (2017) Rewriting the Rules for the Digital Age [online] https://www2.deloitte.com/cn/en/pages/human-capital/articles/global-human-capital-trends2017.html\# (accessed 12 February 2020).

Denzin, N. (1978) The Research Act: A Theoretical Introduction to Sociological Methods, McGraw-Hill, New York.

Dowling, B. and Richardson, R. (2011) 'Managers in the National Health Service', The International Journal of Human Resource Management, Vol. 8, No. 3, pp.348-366 [online] https://doi.org/10.1080/095851997341685.

Economou, M. (2003) 'Strategic management of cultural institutions', in Vinieratou, M. et al. (Eds.): Collective Volume Cultural Policy and Administration: Cultural Management, Hellenic Open University, Patras.

Emaan, S. and Ali, B. (2020) 'Role of shared vision in an organization: a complexity environment perspective', International Journal of Sustainable Strategic Management, Vol. 8, No. 2, pp.120-137 [online] https:/doi.org/10.1504/IJSSM.2020.111169.

Evangelou, E. (2014). The Use of Methodological Triangulation in the Research of the Quality of Life of the Mentally Ill Living in the Community [online] http://e-jst.teiath.gr/issues/ issue_35/Euaggelou_35.pdf (accessed 7 March 2019).

Fopp, M.A. (1988) Museum \& Gallery Management, Unpublished Doctoral thesis, City University London [online] https://openaccess.city.ac.uk/id/eprint/7538 (accessed 28 December 2019).

Gosetti, G. (2020) 'Innovation and quality of working life: perspectives and dimensions for analysis', International Journal of Work Innovation, Vol. 2, No. 4, pp.284-307 [online] https://doi.org/10.1504/IJWI.2020.111765.

Hartl, E. and Hess, T. (2017) 'The role of cultural values for digital transformation: insights from a Delphi study', Twenty-Third Americas Conference on Information Systems, 10-12 August, Boston.

Hill, L., O’Sullivan., C. and O’Sullivan., T. (2011) Creative Arts Marketing, Routledge, New York.

Jackson, S.E., Schuler, R.S. and Jiang, K. (2014) 'An aspirational framework for strategic human resource management', The Academy of Management Annals, Vol. 8, No. 1, pp.1-56 [online] https://doi.org/10.5465/19416520.2014.872335

Jung, D.I., Chow, C. and Wu, A. (2003) 'The role of transformational leadership in enhancing organizational innovation: hypotheses and some preliminary findings', The Leadership Quarterly, Vol. 14, Nos. 4-5, pp.525-544 [online] https://doi.org/10.1016/S10489843(03)00050-X.

Korhonen, J.J., Collin, J., Hiekkanen, K., Halén, M., Itälä, T. and Helenius, M. (2015) IT Leadership in Transition - The Impact of Digitalization on Finnish Organizations [online] http://urn.fi/URN:ISBN:978-952-60-6243-3 (accessed 27 March 2020).

Kulesz, O. (2014). The Impact of Digital Technologies on the Diversity of Cultural Expressions in Spain and Hispanic America [online] https:/en.unesco.org/creativity/sites/creativity/files/ sessions/10igc_inf4_the_impact_of_digital_technologies_octavio_kulesz_en.pdf (accessed 22 January 2020).

Mialaret, G. (1997) Introduction to Educational Sciences, Tipothito, Athens.

Minichiello, V., Aroni, R., Timewell, E. and Alexader, I. (1995) In Depth Interviewing, Longman, Melbourne. 
Mohapatra, S., Verma, P. and Stocchetti, A. (2020) 'Professionals as the 4th 'P' of sustainability: a sustainable HRM framework with strategic implications', International Journal of Sustainable Strategic Management, Vol. 8, No. 2, pp.159-180 [online] https://doi.org/ 10.1504/IJSSM.2020.111190

Moye, J.M., Henkin, B.A. and Egley, J.R. (2005) 'Teacher-principal relationships: exploring linkages between empowerment and interpersonal trust', Journal of Educational Administration, Vol. 43, No. 3, pp.260-277 [online] https://www.emeraldinsight.com/ doi/abs/10.1108/09578230510594796.

O'Riordan, J. (2017) The Practice of Human Resource Management, State of the Public Service Series, Institution of Public Administration [online] https://www.ipa.ie/ fileUpload/ Documents/THE_PRACTICE_OF_HRM.pdf (accessed 3 January 2020).

Ongori, H. (2009) 'Managing behind the scenes: a view point on employee empowerment', African Journal of Business Management, Vol. 3, No. 1, pp.9-15 [online] http://www.academicjournals.org/AJBM (accessed 9 January 2020).

Papalexandri, N. and Bourantas, D. (2002) Human Resources Management, Benou, Athens.

Paraskevopoulou-Kollia, E.A. (2008) 'Methodology of qualitative research in social sciences and interviews', The Journal for Open and Distance Education and Educational Technology, Vol. 4, No. 1 [online] https://doi.org/10.12681/jode.9726

Porter, M. (1996) 'What is strategy?', Harvard Business Review, Vol. 74, No. 6, pp.61-78, Hellenic Open University, Patras.

Potterfield, T.A. (1999) The Business of Employee Empowerment: Democracy and Ideology in the Workplace, Quorum Books, Westport, Conn.

Pradhan, R. and Panda, M. (2019) 'Human resource empowerment: development and validation of a measurement tool', Global Business Review, Vol. 1, No. 19, pp.1-19 [online] https://doi.org/10.1177/0972150918816895.

Sageer, A., Rafat, S. and Agarwal, P. (2012) 'Identification of variables affecting employee satisfaction and their impact on the organization', Journal of Business and Management, Vol. 5, No. 1, pp.32-39 [online] http://www.iosrjournals.org (accessed 19 April 2019).

Salamzadeh, Y., Kianmanesh., M. and Vahidi, T. (2019) 'Transformational leadership style and social responsibility of employees in economic corporations: a study on Sarmayeh Bank of Iran', International Journal of Sustainable Strategic Management, Vol. 7, Nos. 1-2, pp.186-203 [online] https://doi.org/10.1504/IJSSM.2019.099042.

Snell, S.A., Youndt, M.A. and Wright, P.M. (1996) 'Establishing a framework for research in strategic human resource management: merging resource theory and organizational learning', in Ferris, G. (Ed.): Research in Personnel and Human Resources Management, Vol. 14, pp.61-90, JAI, Greenwich, CT.

Spiraki, C. and Spirakis, G. (2008) Empowerment of Human Resources as a Factor for Improving Organizational Performance [online] https://www.researchgate.net/publication/282442483 E_Endynamose_tou_Anthropinou_Dynamikou_os_Paragontas_Beltioses_tes_Organosiakes_ Apodoses (accessed 28 June 2019).

Ulrich, D. (1997) Human Resource Champions: The Next Agenda for Adding Value and Delivering Results, Harvard Business Press, USA.

Uslu, T. (2015) 'Innovation culture and strategic human resource management in public and private sector within the framework of employee ownership', Procedia - Social and Behavioral Sciences, Vol. 195, pp.1463-1470 [online] https://doi.org/10.1016/j.sbspro.2015.06.445.

Verma, J. (2012) 'Strategic human resource management: a choice or compulsion?', European Journal of Business and Management, Vol. 4, No. 3 [online] http://iiste.org/Journals/ index.php/EJBM/article/viewFile/1046/966.

Vrasidas, C. (2020) Education as the Main Component of Managing Talented Employees in the Digital Age [online] https://epale.ec.europa.eu/el/blog/i-ekpaideysi-os-kyrio-systatiko-tisdiaheirisis-talantoyhon-ergazomenon-stin-psifiaki-epohi (accessed 20 February 2020). 
Xirotiri-Koufidou, S. (2001) Human Resource Management. The Challenge of the 21st Century in the Working Environment, Anikoula, Athens.

Yean, T.F. and Yahya, K.K. (2013) 'The influence of malaysian insurance agents career planning on their career strategies', International Journal of E-Education, Vol. 3, No. 1, pp.23-28 [online] http://doi.org/10.7763/IJEEEE.2013.V3.187.

\section{Notes}

1 See http://www.otaru-uc.ac.jp/ js/downloads/SP2005-PDF/SP2005-Chapter2SHRM.pdf.

2 More at http://www.otaru-uc.ac.jp/ js/downloads/SP2005-PDF/SP2005-Chapter2SHRM.pdf.

3 More at https://www.euractiv.gr/section/koinoniki-eyropi/news/etisio-synedrio-europeanapsifiakos-metaschimatismos-ston-politismo/.

4 http://www.lykelkal.gr/organosi-kai-dioikisi/dioikitiko-symvoulio/.

5 The data was extracted both from the KLCoGW website and from the interview with Mrs. A. Mavrou.

6 Data from the interview with Mrs. Mavrou.

7 Data from the interview with Mr. Michos.

8 At this point, it is worth mentioning the great offer of the Founder of the Association, Mrs. Karelia, who actively supports the Association, as a large part of the Association is supported by volunteers.

9 Data from the interview with Mrs. Mavrou.

10 Information from the interview with Mrs. Kanellopoulou. A typical example of attracting, evaluating and selecting staff of the KLCoGW is the cheerleader Mrs. Kanellopoulou. Her choice was through assessment procedures with other candidates, with postgraduate and equivalent experience in the field. She also reports that, in addition to supporting the strengthening of her role by the KLCoGW, she is also personally trained in her own, following the latest news in the field through lectures, seminars, etc.

11 Head of People and Change KPMG in Singapore https://assets.kpmg/content/dam/kpmg/ sg/pdf/2019/05/cultural-transformation-in-the-digital-world.pdf. 